\title{
Glyphosate Detection: An Innovative Approach by Using Chemoresistive Gas Sensors ${ }^{\dagger}$
}

\author{
Barbara Fabbri 1,*, Matteo Valt 1,*, Andrea Gaiardo ${ }^{1,2}$, Sandro Gherardi 1 , Cesare Malagù ${ }^{1}$ and \\ Vincenzo Guidi ${ }^{1}$ \\ 1 Department of Physics and Earth Sciences, University of Ferrara, 44122 Ferrara, Italy; \\ andrea.gaiardo@unife.it (A.G.); gherardi@fe.infn.it (S.G.); malagu@fe.infn.it (C.M.); guidi@fe.infn.it (V.G.) \\ 2 Micro Nano Facility, Bruno Kessler Foundation, 38123 Trento, Italy \\ * Correspondence: barbara.fabbri@unife.it (B.F.); matteo.valt@unife.it (M.V.); Tel.: +39-0532-974213 \\ † Presented at the Eurosensors 2018 Conference, Graz, Austria, 9-12 September 2018.
}

Published: 27 Novemebr 2018

\begin{abstract}
Glyphosate is the most frequently used herbicide worldwide, its hazard potential is unclear and nowadays a threshold limit value has not yet been determined. We used eight chemoresistive gas sensors based on semiconducting nanopowders for the identification of $\mathrm{N}$ (phosphonomethyl) glycine in air. The sensors were tested at their proper working temperature in presence of volatile glyphosate at concentrations within the range of $6 \mathrm{ppb}-1 \mathrm{ppm}$, i.e., a plausible interval of interest for its monitoring. The sensing material that best performed was a solid solution of Tungsten oxide and Tin oxide (WS30). This study opens up to design portable devices suitable for monitoring glyphosate concentrations at which workers and people are exposed.
\end{abstract}

Keywords: glyphosate; chemoresistive gas sensors; semiconducting nanopowders

\section{Introduction}

Glyphosate is typically applied as weed control to roadsides and other areas and used as a preharvest desiccant. Persons that are most likely to be exposed to glyphosate are operators of the herbicide spraying vehicle and potentially persons waiting, walking or driving along the roadside behind the applicator truck. The mean half-life of glyphosate has been reported as 32 days in forests and row crops but varies considerably as a function of microbial activity, soil $\mathrm{pH}$ and temperature [1]. Despite the potentiality as herbicide, recently many studies have questioned that glyphosate causes an ecotoxicological impact and a human risk [2]. It is a challenge to identify glyphosate. Indeed, it is highly soluble in water, but at all in common organic solvents, it has high polarity, no chromophoric groups are present in its molecular structure making its analytical detection difficult, and its vapor pressure is very low then its identification in air is problematic. Numerous analytical methods to track glyphosate in the environment as well as in body fluids have been developed. Despite their highly sensitive and accurate detection, many of these methods are costly, timeconsuming or require extensive instrumentation and they are based on an adsorptive removal approach of glyphosate. In particular, the most used techniques are gas and liquid chromatography (GC and LC), especially based on derivatising agents [3,4]. Immunosensors, optical and colorimetric sensors represent an effective alternative together with more innovative methods, such as electronic tongue in water $[5,6]$. The occurrence and behavior of atmospheric transport of glyphosate are still largely unknown even though glyphosate is the most widely used herbicide in the world. Moreover, in Europe there are not any defined threshold limit value (TLV). Therefore, it become peremptory to provide an approach that allows the evaluation of glyphosate concentration in the air we breathe. 


\section{Materials and Methods}

\subsection{Sensing Materials}

For the present work, eight chemoresistive gas sensors were tested as simple and cost-effective alternative to detect different concentrations of glyphosate in air. The sensing films were prepared synthetizing different materials [7,8]: two sensors based on a solid solution of tin, titanium and niobium oxides (named STN), two on tungsten oxide and tin oxide (named WS30), one on tin oxide and molybdenum oxide (named SnMo), two on tin oxide and titanium oxide (named ST20), and one on zinc oxide. Thus, the sensing films were morphologically and chemically characterized (Zeiss EVO 40 microscope scope with an acceleration voltage of $20 \mathrm{kV}$ ), then screen-printed onto alumina substrates with interdigitated gold electrodes on the front side and a platinum heater on the rear side.

\subsection{Glyphosate Sensing Measurements}

Since glyphosate is mainly used in water solution, we have developed a simple setup capable to mix wet air and a glyphosate aerosol. Synthetic air from certified bottle was firstly fluxed through a water filled bubbler and injected in the measurements chamber in order to achieve a stable baseline, then, the main carrier was mixed with another dry air flux passing through another bubbler filled with a solution of glyphosate, modulating as it the analyte concentration in the gas flow (Figure 1).

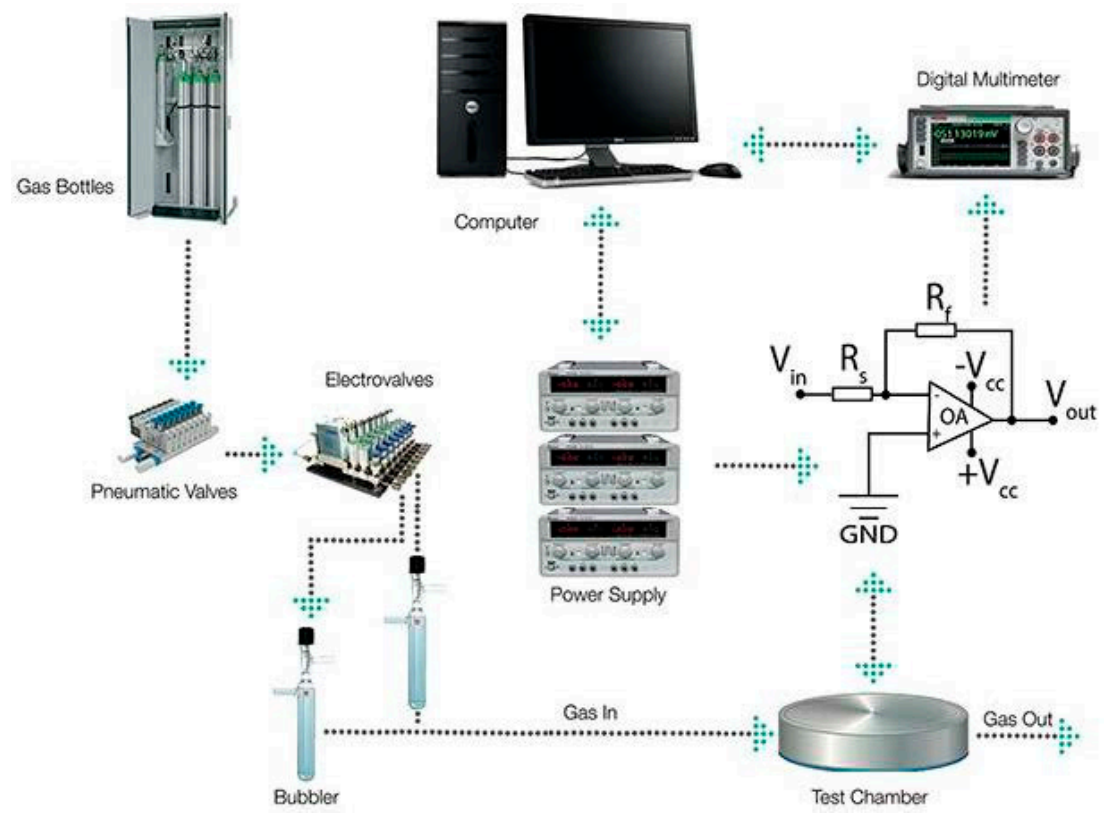

Figure 1. Schematization of the employed experimental setup.

The sensor response is calculated as calculated as $\left(G_{g l y p h o}-G_{\text {air }}\right) / G_{\text {air }}$, where $G_{g}$ lypho is the sensor conductance during the exposure to glyphosate and $G_{a i r}$ is the conductance in presence only of wet air. Indeed, the voltage signal recorded by means of the electronic acquisition system is directly proportional to the sensing film conductance. Different Relative Humidity (\%RH) conditions were tested spanning through $40 \%$ to $60 \% \mathrm{RH}$ at $35^{\circ} \mathrm{C}$.

The majority of analytical techniques used, such as GC and LC, reach sub-ppm LOD (Limit of Detection) [4]. Therefore, in order to guarantee a high standard quality measurement and to arrange an innovative competitive monitoring technique, in this study we identify glyphosate concentrations in the $6 \mathrm{ppb}-1$ ppm range. 


\section{Results and Discussion}

\subsection{Sensing Materials}

Scanning Electron Microscopy (SEM) analysis revealed a spherical-like morphology for each sensing material used with grains size in the order of $100 \mathrm{~nm}$ (Figure 2a). Each sensor was tested at its proper working temperature (see Table 1), identified through a suitable calibration of heater devices (Figure $2 b$ ).

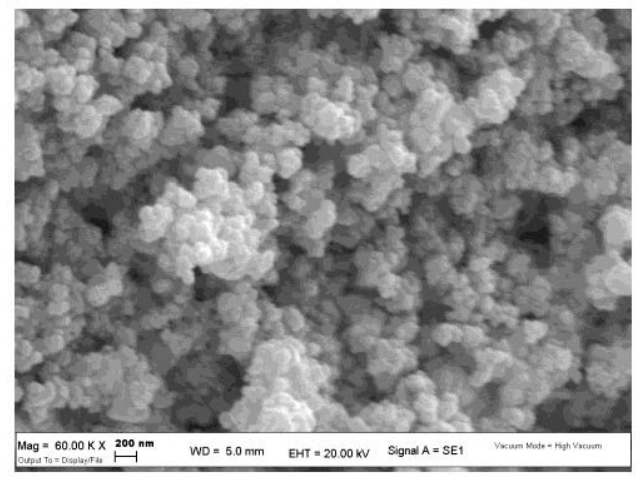

(a)

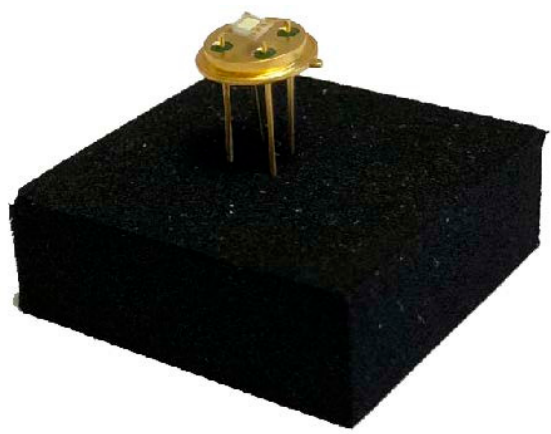

(b)

Figure 2. (a) SEM image of nanostructured WS30 based-sensor; (b) WS30 sensor packaged on a TO39 support to ease the connection with the electronic acquisition system.

Table 1. Working temperatures applied to the sensors selected. ST20 Si sensor placed in channel 6 was produced with a silicon micromachining substrate.

\begin{tabular}{ccccccccc}
\hline Channel & CH1 & CH2 & CH3 & CH4 & CH5 & CH6 & CH7 & CH8 \\
\hline Sensor & STN & WS30 & SnMo & ZnO & ST20 & ST20 Si & WS30 & STN \\
\hline Working Temperature $\left[{ }^{\circ} \mathrm{C}\right]$ & 450 & 450 & 400 & 450 & 450 & 450 & 450 & 450 \\
\hline
\end{tabular}

\subsection{Glyphosate Sensing in Air}

Among the eight sensors exposing to different concentrations of glyphosate, the best performance were obtained with WS30 based-sensor. Figure 3a shows the dynamic response of this device to decreasing values of glyphosate concentration.

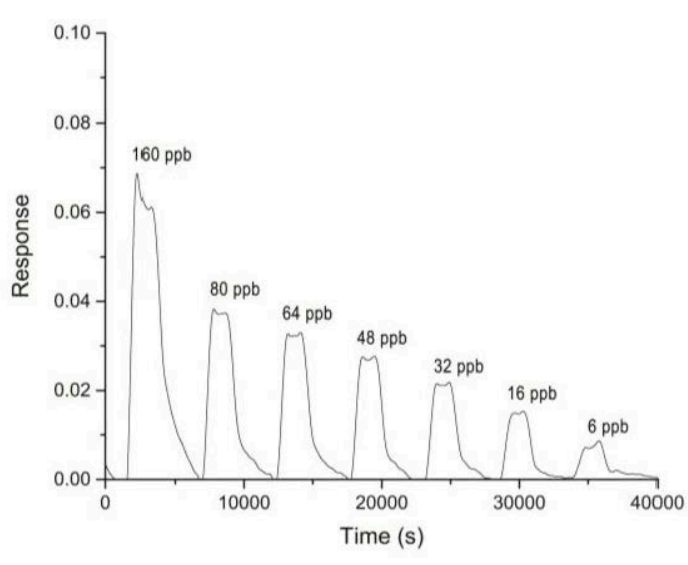

(a)

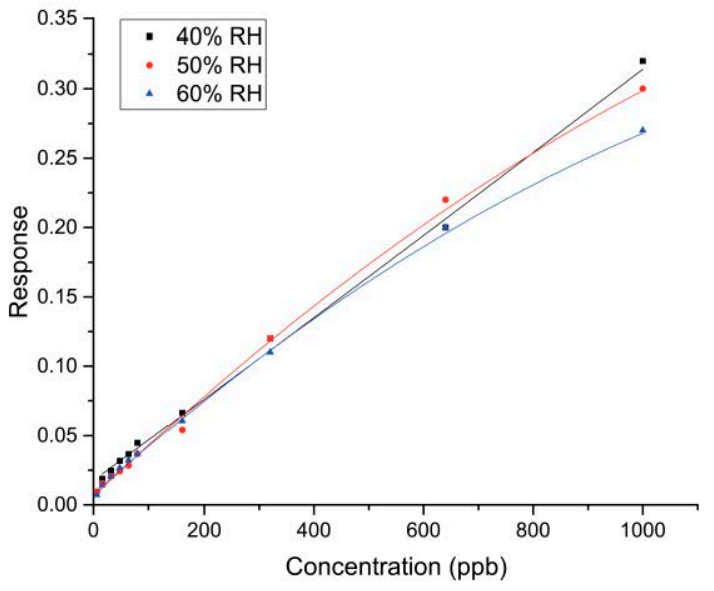

(b)

Figure 3. (a) Dynamic response of WS30 (CH7) sensor to different glyphosate concentrations at $60 \% \mathrm{RH}$ and $35^{\circ} \mathrm{C}$ (test chamber conditions); (b) Calibration curves of WS30 sensor for different \% RH values. 
One can observe that the signal is stable and completely reaches the baseline at each air injection. The response and the recovery times are in the order of 5-10 $\mathrm{min}$, in line with other semiconducting materials used as sensing film for such applications.

Three calibration curves were obtained for three \%RH values (Figure 3b). Up to $300 \mathrm{ppb}$, it seems that WS30 response was not affected by the humidity variation. Exposing the sensor to higher glyphosate concentrations, the three calibration curves follow different trends. Indeed, the response decreases for increasing humidity values, common behavior for sensing devices based on metal-oxide semiconductors. In particular, it is significant that at $40 \% \mathrm{RH}$ the variation of WS30 response is almost linear.

\section{Conclusions}

Nowadays, the monitoring of glyphosate has become crucial due to its impact on environmental and human health. In this work, an innovative approach for glyphosate detection has been proposed. Among five different sensing materials, the solid solution of tungsten oxide and tin oxide resulted to be promising for this purpose, showing sensing performance perfectly in line with those of sensors used for environmental applications. This is a preliminary study, but it opens up to a new method to control the presence of this problematic compound in the atmosphere.

Author Contributions: B.F. and M.V. conceived and designed the experiments; M.V. performed the experiments; A.G. and S.G. analyzed the data; V.G. and C.M. contributed reagents/materials/analysis tools; B.F. wrote the paper.

Conflicts of Interest: The authors declare no conflict of interest.

\section{References}

1. Franz, J.E.; Mao, M.K.; Sikorski, J.A. Glyphosate: A Unique Global Herbicide; American Chemical Society: Washington, DC, USA, 1997; Chapter 4, pp. 65-97, ISBN 0841234582.

2. Portier, C.J.; Armstrong, B.K.; Baguley, B.C.; Baur, X.; Belyaev, I.; Budnik, L.T. Differences in the carcinogenic evaluation of glyphosate between the International Agency for Research on Cancer (IARC) and the European Food Safety Authority (EFSA). J. Epidemiol. Community Health 2016, 70, 741-745, doi:10.1136/jech-2015-207005.

3. Gill, J.P.K.; Sethi, N.; Mohan, A. Analysis of the glyphosate herbicide in water, soil and food usingderivatising agents. Environ. Chem. Lett. 2017, 15, 85-100, doi:10.1007/s10311-016-0585-z.

4. Ding, J.; Guo, H.; Liu, W.; Zhang, W.; Wang, J. Current progress on the detection of glyphosate in environmental samples. J. Sci. Appl. Biomed. 2015, 3, 88-95.

5. González-Martínez, M.A.; Brun, R.; Puchades, E.M.; Maquieira, A.; Ramsey, K.; Rubio, F. Glyphosate Immunosensor. Application for Water and Soil Analysis. Anal. Chem. 2005, 77, 4219-4227, doi:10.1021/ac048431d.

6. Bataller, R.; Campos, I.; Laguarda-Miro, N.; Alcañiz, M.; Soto, J.; Martínez-Máñez, R.; Gil, L.; García-Breijo, E.; Ibáñez-Civera, J. Glyphosate Detection by Means of a Voltammetric Electronic Tongue and Discrimination of Potential Interferents. Sensors 2012, 12, 17553-17568, doi:10.3390/s121217553.

7. Guidi, V.; Malagu', C.; Carotta, M.C.; Vendemiati, B. Printed semiconducting gas sensors. In Printed Films: Materials Science and Applications in Sensors, Electronics and Photonics; Woodhead Publishing Series in Electronic and Optical Materials; Woodhead Publishing Ltd.: Cambridge, UK, 2012; Chapter 11, pp. 278-334, doi:10.1533/9780857096210.2.278.

8. Guidi, V.; Carotta, M.C.; Fabbri, B.; Gherardi, S.; Giberti, A.; Malagù; C Array of sensors for detection of gaseous malodors in organic decomposition products. Sens. Actuators B 2012, 174, 349-354, doi:10.1016/J.SNB.2012.07.013.

(C) 2018 by the authors. Licensee MDPI, Basel, Switzerland. This article is an open access article distributed under the terms and conditions of the Creative Commons Attribution (CC BY) license (http://creativecommons.org/licenses/by/4.0/). 